\title{
Antioxidant Capacity and Bioactive Contents of Mulberry Species from Eastern Anatolia Region of Turkey
}

\author{
Muttalip Gundogdu', Murat Tunçtürk ${ }^{2}$, Selma Berk ${ }^{3}$, Nazım Şekeroğlu ${ }^{4}$, Sevgi Gezici ${ }^{5}$ \\ ${ }^{1}$ Department of Horticulture, Faculty of Agriculture and Natural Sciences, Abant Izzet Baysal University, Bolu, TURKEY. \\ ${ }^{2}$ Field Crops Department, Yuzuncu Yıl University, Agricultural Faculty, Van, TURKEY \\ ${ }^{3}$ Department of Plant and Animal Production, Mudurnu Sureyya Astarcı Vocational school, Abant Izzet Baysal University, \\ Bolu, TURKEY. \\ ${ }^{4}$ Department of Food Engineering, Kilis 7 Aralık University, Engineering and Architecture Faculty, Kilis, TURKEY. \\ ${ }^{5}$ Department of Molecular Biology and Genetics, Kilis 7 Aralık University, Science and Art Faculty, Kilis, TURKEY.
}

\begin{abstract}
In this study, we aimed to determine biochemical contents of white (Morus alba L.) and black (Morus nigra L.) mulberry genotypes grown in the Hakkari region. At the end of the study, organic acids, phenolic compounds, sugars, vitamin $\mathrm{C}$ and antioxidant capacities of mulberry species were determined. Black mulberry genotypes were found to contain higher antioxidant capacity than white mulberry genotypes. The highest antioxidant capacity was detected in the 30 YKO3 $(25.55 \mu \mathrm{molTE} / \mathrm{g})$ black mulberry genotype. While phenolic compounds varied in mulberry species, especially gallic acid $(57.78 \mathrm{mg} / 100 \mathrm{~g})$, chlorogenic acid $(53.13 \mathrm{mg} / 100 \mathrm{~g})$, and rutin $(37.77 \mathrm{mg} / 100 \mathrm{~g})$ had the highest values. Malic acid was found to be higher than other organic acids and was found to be 13.51 $\mathrm{g} / 100 \mathrm{~g}$ in the highest $30 \mathrm{HKO} 3$ genotype. Although sugar contents varied in mulberry species, glucose was determined higher than fructose and sucrose in mulberries.
\end{abstract}

Key words: Mulberry, Phenolic compounds, Organic acids, Sugars.

\section{INTRODUCTION}

The mulberry belongs to the genus of Morus, is a tropical and subtropical fruit species. Growing in different climatic and soil conditions has increased its spread over the world. Although the main center of the mulberry in the world is China ${ }^{1}$ It is one of the important centers where mulberry cultivation is made in Turkey. The most common species of mulberry in this country are Morus alba, Morus nigra and Morus rubra., ${ }^{2,3}$ In addition to the low fresh consumption of mulberry produced by this production, the mulberry fruit is mostly used in making molasses, pestil, kome, jam and vinegar. Black mulberry consumption in the paste and ice cream sector has become widespread as a natural color and flavor. ${ }^{2,4}$ Moreover, the anthocyanins and the higher antioxidant capacity it possesses have also increased the consumption in terms of health., ${ }^{5,6}$ Ecological factors affect the content of organic acids, sugars and phenolic substances in plants, as well as genetic factors. ${ }^{3,6}$ It is known that in the eastern part of Turkey there are few studies related to the physicochemical properties of mulberries. ${ }^{7}$ However, no work has been found on the mulberries of Hakkari region. In this study, it was aimed to determine organic acids, sugar and phenolic content and the antioxidant activities of black and white mulberry genotypes in Hakkari region of Turkey.

Fruits samples

In this study, eight genotype of Morus alba L. and Morus rubra L. (30HK01, 30HK02,

\section{MATERIALS AND METHODS}

Submission Date: 30-08-2016; Revision Date: 17-11-2016; Accepted Date: 23-11-2016

DOI: 10.5530/ijper.52.4s.82 Correspondence: Murat Tunçtürk,

Yuzuncu Yil University, Agricultural Faculty, Field Crops Department, Van-TURKEY.

Phone: +90 4324445065 E-mail: murattuncturk@ hotmail.com

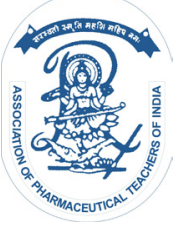

www.ijper.org 
30HK03, 30HK04, 30YK01, 30YK02, 30YK03, 30YK04) were used. These genotypes were grown in the Hakkari region. Harvest was made in 2014 when the fruits of examined cultivars and genotypes grew to completely ripe.

\section{Analysis of phenolic acids}

Phenolic compounds were detected among phenolic acids in mulberry fruits, with the modified method of Rodriguez-Delgado et al. ${ }^{8}$ Fruit extracts were mixed with distilled water in a ratio of 1:1. The mixture was centrifuged for $15 \mathrm{~min}$ at $15000 \mathrm{rpm}$. Supernatants were filtrated with coarse filter paper and twice with $0.45 \mu \mathrm{m}$ membrane filter (Millipore Millex-HV Hydrophilic PVDF, Millipore, USA), and injected into an HPLC (Agilent. USA). Chromatographic separation was performed with a $250 \times 4.6 \mathrm{~mm}, 4 \mu \mathrm{m}$ ODS column (HiChrom, USA). Solvent A methanol:acetic acid:water (10:2:28) and Solvent B methanol:acetic acid:water (90:2:8) were used as the mobile phase. Spectral measurements were made at 254 and $280 \mathrm{~nm}$, and flow rate and injection volume were adjusted to $1 \mathrm{ml} \mathrm{min}^{-1}$ and $20 \mu$, respectively.

\section{Analysis of organic acids}

Organic acids were identified by Bevilacqua and Califano. ${ }^{9}$ Juice extracts were obtained by mashing the berries in cheesecloth, after which the samples were stored at $-20^{\circ} \mathrm{C}$ until analyzed. $5 \mathrm{ml}$ of each sample was mixed with $20 \mathrm{ml}$ of $0.009 \mathrm{~N} \mathrm{H}_{2} \mathrm{SO}_{4}$ (Heidolph Silent Crusher $\mathrm{M}$, Germany), then homogenized for $1 \mathrm{~h}$ with a shaker (Heidolph Unimax 1010, Germany). The mixture was centrifuged for $15 \mathrm{~min}$ at $15000 \mathrm{rpm}$, and supernatants were filtrated twice with $0.45 \mu \mathrm{m}$ membrane filter following filtration with coarse filter (Millipore Millex-HV Hydrophilic PVDF, Millipore, USA) and run through a SEP-PAK C18 cartridge. Organic acid readings were performed with HPLC using Aminex column (HPX 87 H, 300 mm x 7.8 mm, Bio-Rad Laboratories, Richmond, CA, USA) at 214 and $280 \mathrm{~nm}$ wavelengths, on Agilent package program (Agilent, USA).

\section{Analysis of vitamin C}

Vitamin C content was detected with modified HPLC procedure suggested by Cemeroglu. ${ }^{10} 5 \mathrm{ml}$ of the fruit extracts was supplemented with $\% 2.5(\mathrm{w} / \mathrm{v})$ metaphosphoric acid (Sigma, M6285, 33.5\%), then centrifuged at $6500 \mathrm{rpm}$ for $10 \mathrm{~min}$ at $4^{\circ} \mathrm{C}$ temperature. $0.5 \mathrm{ml}$ of the mixture was bring to final volume of $10 \mathrm{ml}$ with $\% 2.5$ (w/v) metaphosphoric acid. Supernatants were filtered with $0.45 \mu \mathrm{m}$ PTFE syringe filter (Phenomenex, UK). $C_{18}$ column (Phenomenex Luna C18, $250 \times 4.60$ $\mathrm{mm}, 5 \mu$ ) was used for the identification of ascorbic acid at temperature of $25^{\circ} \mathrm{C}$. Double distilled water with $1 \mathrm{~mL} / \mathrm{min}$ flow rate and $\mathrm{pH}$ of 2.2 (acidified with $\mathrm{H}_{2} \mathrm{SO}_{4}$ ) was used as a mobile phase. Spectral measurements were made at $254 \mathrm{~nm}$ wavelength using DAD detector. Different standards of L-ascorbic acid (Sigma A5960) (50, 100, 500, 1000, and 2000 ppm) were used for quantification of ascorbic acid readings.

\section{Determination of trolox equivalent antioxidant capacity (TEAC)}

Trolox equivalent antioxidant capacity (TEAC) was determined with ABTS (2, 2-Azino-bis-3-ethylbenzothiazoline-6-sulfonic Acid) by dissolving in acetate buffer using potassium per sulphate. ${ }^{11}$ For longer stability, the mixture was diluted with $20 \mathrm{mM}$ sodium acetate buffer in acidic $\mathrm{pH}$ of 4.5 and read at $734 \mathrm{~nm}$ wavelength $(0.700$

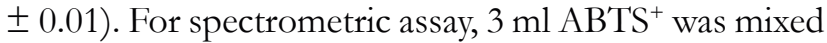
with $20 \mu \mathrm{l}$ fruit extract sample and incubated for $10 \mathrm{~min}$, at $734 \mathrm{~nm}$ wavelengths for absorbance detection.

\section{Sugar Analysis}

The modified method of Melgarejo et al. ${ }^{12}$ was used for sugar analyses. $5 \mathrm{~mL}$ of fruit extracts was centrifuged at $12000 \mathrm{rpm}$ for $2 \mathrm{~min}$ at temperature of $4^{\circ} \mathrm{C}$. Supernatants were passed by SEP-PAK $\mathrm{C}_{18}$ cartridge. HPLC readings were made with $\mu$ bondapak- $\mathrm{NH}_{2}$ column using $85 \%$ acetonitrile as liquid phase with refractive index detector (IR). Fructose and glucose standards were used for sugar calculations.

\section{Statistical Analysis}

Three replicates including 30 fruits per replicate were used. Descriptive statistics of phenolic compounds, organic acids, sugars, vitamin $\mathrm{C}$, and antioxidant capacity extracted from cultivars and genotypes were represented as Mean \pm SE. Experimental data were evaluated using analysis of variance ANOVA and significant differences among the means of three replicates $(p<0.005)$ were determined by Duncan's multiple range test, using the SPSS 20 for Windows.

\section{RESULTS AND DISCUSSION}

When the organic acid values were examined, statistically differences $(P<0.05)$ between the varieties were found. Malic acid was the major organic acid for all the mulberry genotypes. It was followed citric and succinic acid and fumaric acid was determined the lowest level organic acid. Malic acid levels were ranged from 7.13 to $13.51 \mathrm{~g}$ $100 \mathrm{~g}^{-1} \cdot 30 \mathrm{HK} 03$ white mulberry genotype was found to have highest oxalic, malic, succinic and fumaric acid than other genotypes. It was determined that white mulberry contain more organic acids value than black mulberry except for citric acid. Bozhöyük et al. ${ }^{13}$ were determined 
that malic acid was predominant acid in white mulberry while citric acid was the major acid in the black mulberry. In harmony with our results, Eyduran et al. ${ }^{4}$ in Turkey, Aljane and Sdiri ${ }^{14}$ in Tunisia found that the highest level acid was malic acid among the organic acids. However, in another study in China, it was reported that succinic acid was the highest level acid $(6.48 \mathrm{mg} / \mathrm{g} \mathrm{fw})$ among the organic acids. ${ }^{15}$ Although our study is in compliance with some other studies, it is considered that there are differences depending on cultivars and geographical conditions.

Vitamin $\mathrm{C}$ and total antioxidant values were differed significantly by cultivars. White mulberries contained more vitamin $C$ level compared to black mulberries. The highest vitamin $C$ value $\left(30.45 \mathrm{mg} 100 \mathrm{~g}^{-1}\right)$ was measured in $30 \mathrm{HK} 02$ white mulberry but this genotype possessed the lowest total antioxidant value. 30YK03 black mulberry genotype had the lowest vitamin $\mathrm{C}$ and the highest total antioxidant value $\left(25.55 \mu\right.$ molTE g $\left.^{-1}\right)$. Black mulberries had more total antioxidant level than white mulberries (Table 1). Iqbal et al. ${ }^{16}$ conducted a study on black, white and red mulberries in Pakistan and identified vitamin $\mathrm{C}$ as $25.2-32.25 \mathrm{mg} 100 \mathrm{~g}^{-1}$. The study conducted in Turkey, vitamin $\mathrm{C}$ value in white mulberries was determined two times higher than black mulberries. ${ }^{3}$ These researches were identified total antioxidant value as 4.49-13.99 $\mu$ molTE g ${ }^{-1}$. Although there were numerical differences compared to our research, they reported that black mulberries contained more TEAC than white mulberries. Similarly, according to Khalid., ${ }^{17}$ black mulberries had total antioxidant value as 14-20 $\mu$ molTE $\mathrm{g}^{-1}$. Compared to our study, Kamiloglu et al. ${ }^{18}$ measured higher TEAC value in black mulberries while Arfan et al..$^{19}$ recorded lower TEAC value in mulberries. It is thought that the difference between these studies and our study is caused by ecological and genetic factors. The sugar contents were as follows: glucose $>$ fructose $>$ sucrose. Glucose content was recorded about eight times higher than sucrose while fructose content was recorded about five times higher than sucrose. The highest glucose and fructose value was measured in

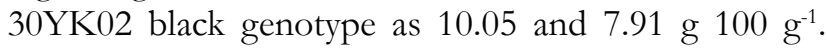
$30 \mathrm{BS} 04$ genotype had the lowest glucose and sucrose level. The amount of sugar in black mulberries was identified more than white mulberries (Table 1). The differences among cultivars might be caused by geographical conditions and genetic factors. Lee and Hwang 20 conducted a study in Morus alba and they found glucose value as 10.8 , fructose value as 12.5 and sucrose value $3.3 \mathrm{~g} 100 \mathrm{~g}^{-1}$. Ozgen et al..$^{7}$ determined major sugar as glucose, while Sanchez et al. ${ }^{21}$ determined major sugar as fructose. These researchers conducted a study in Turkey found glucose content as $5.81 \mathrm{~g} / 100 \mathrm{ml} .^{7}$ On the other hand, in parallel with our research, it was stated

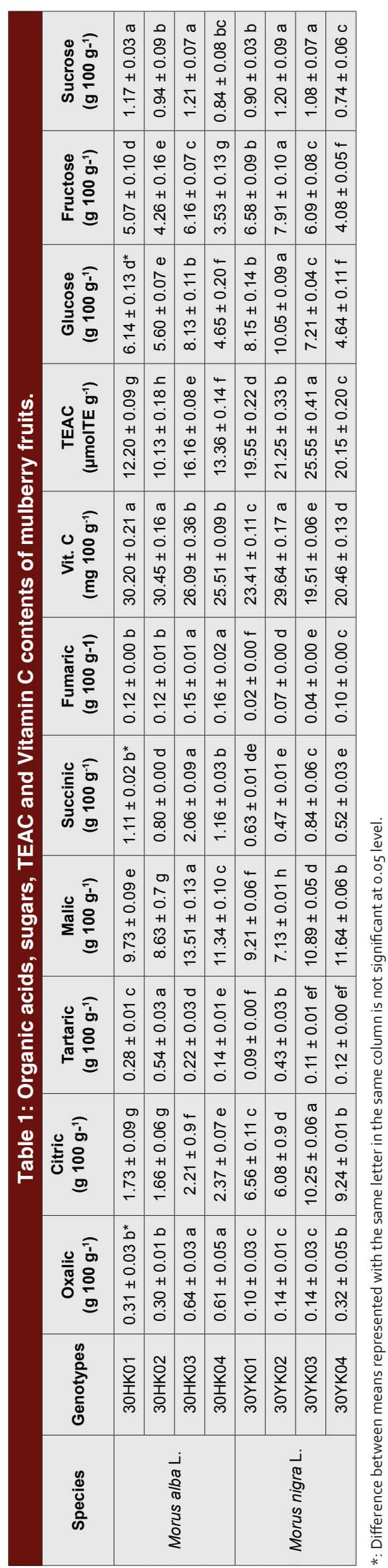



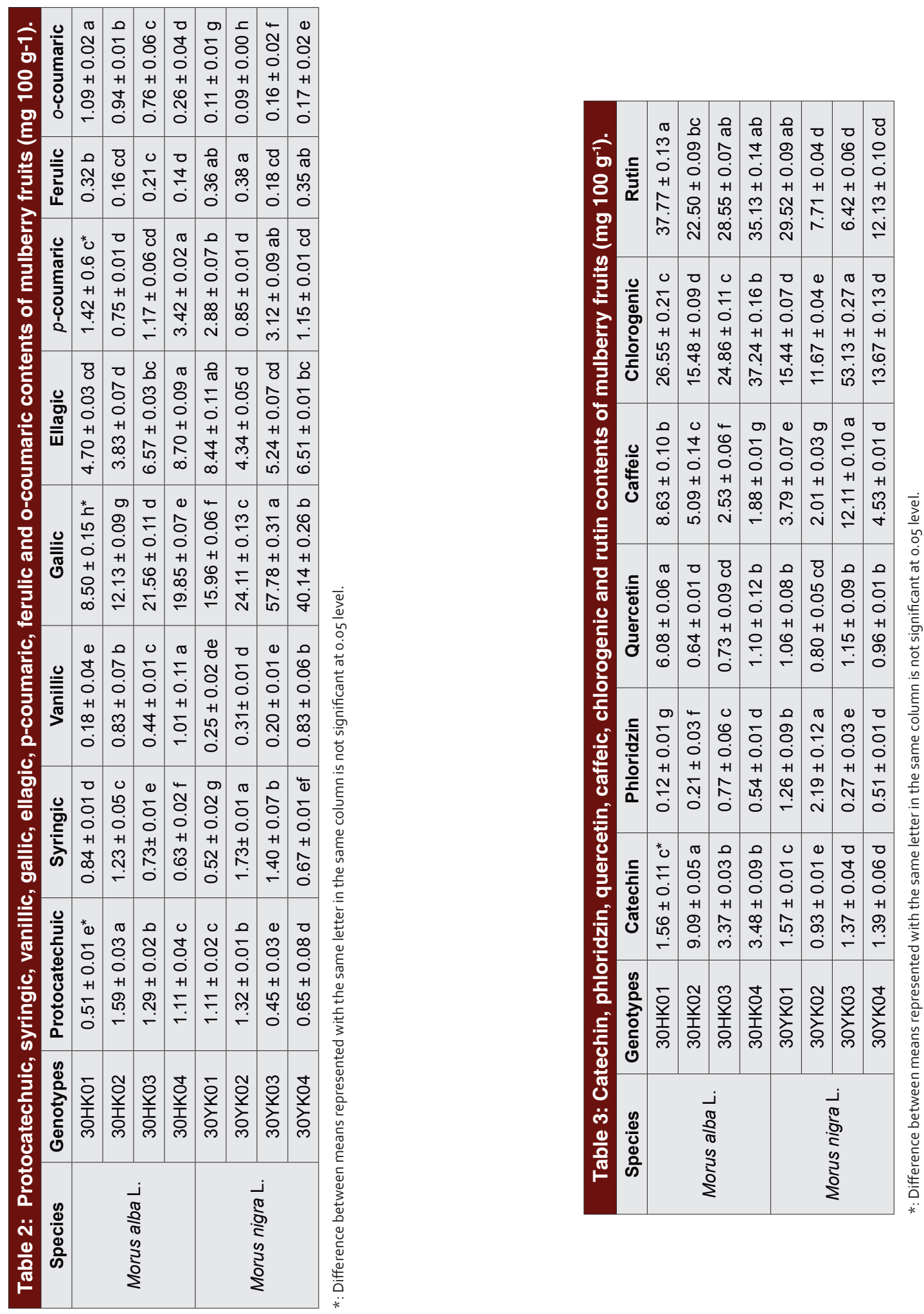
in another study, black mulberries had more sugar than white mulberries. ${ }^{22}$ The phenolic compounds of the mulberry fruit were examined and statistical differences were found to be significant. The phenolic acids (Table 2 and 3) and flavonoids values changed according to the variety. It was determined that the lowest level phenolic compound was ferulic acid. Black mulberries had more phenolic compounds level than white mulberries. 30HK01, 30HK04, 30YK02 and 30YK03 mulberry genotypes had the highest level phenolic compounds. A study conducted in North Serbia, researchers were stated that the highest protocatechuic, gallic and ellagic acid value were $7.94,0.86$ and $2.39 \mathrm{mg} / \mathrm{kg}$ respectively. ${ }^{23}$ Mahmood et al. ${ }^{24}$ determined vanillic acid

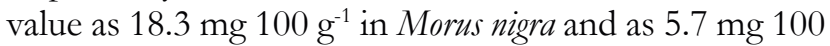
$\mathrm{g}^{-1}$ in Morus alba. Natic et al. ${ }^{23}$ were determined that the highest phenolic compound was rutin as $77.25 \mathrm{mg} / \mathrm{kg}$. In Turkey, Gundogdu et al. ${ }^{3}$ found that phloridzin value ranged from $0.011-0.031 \mathrm{mg} / \mathrm{g}$ and the catechin value of black mulberries measured as $0.075 \mathrm{mg} / \mathrm{g}$. In another study, researchers were reported that quercetin content

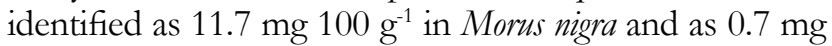
$100 \mathrm{~g}^{-1}$ in Morus alba. ${ }^{24}$

\section{CONCLUSION}

As a result of the study, it was determined that $30 \mathrm{HK} 03$ genotype of white mulberry had the highest content of organic acid and sugar content and as well as significant amount total antioxidant value. The highest total antioxidant and phenolic content was obtained from the $30 Y K 03$ genotype in black mulberry. It was concluded that these two genotypes would be useful for human health. As a result, it is thought that $30 \mathrm{HK} 03$ and 30 YK03 genotypes should be given to farmers, breeders and consumers.

\section{CONFLICT OF INTEREST}

The authors declare no conflict of interest.

\section{ABBREVIATIONS}

HPLC: High Performance Liquid Chromatography; DAD: Diode-Array Detection; ABTS: 2,2-Azino-bis3-ethylbenzothiazoline-6-sulfonic Acid; IR: refractive index detector; TEAC: Trolox equivalent antioxidant capacity.

\section{REFERENCES}

1. Butt MS, Nazir A, Sultana MT, Schroen K. Morus Alba L. nature's functional tonic. Trends in Food Science and Technology. 2008;19(10):505-12.

2. Ercisli S. A short review of the fruit germplasm resources of Turkey. Genetic Resources and Crop Evaluation. 2004;51(4):419-35.

3. Gundogdu M, Muradoglu F, Gazioglu Sensoy RI, Yilmaz H. Determination of fruit chemical properties of Morus nigra $L$, Morus alba $L$, Morus rubra $L$, by HPLC. Scientia Horticulturae. 2011;132:37-41.
4. Eyduran SP, Ercisli S, Akin M, Beyhan O, Gecer MK, Eyduran E, et al. Organic acids, sugars, vitamin $\mathrm{C}$, antioxidant capacity, and phenolic compounds in fruits of white (Morus alba L.) and black (Morus nigra L.) mulberry genotypes. Journal of Applied Botany and Food Quality. 2015;88:134-8.

5. Contessa C, Mellano MG, Beccaro GL, Giusiano A, Botta R. Total antioxidant capacity and total phenolic and anthocyanin contents in fruit species grown in Northwest Italy. Scientia Horticulturae. 2013;160:351-7.

6. Bae S, Suh H. Antioxidant activities of five different mulberry cultivars in Korea. LWT. 2007;40(6):955-62.

7. Gezici S, Tuncturk M, Sekeroglu N. Antibacterial, Antifungal and Antioxidant Activities of the Extracts from Turkish Mulberries. $9^{\text {th }}$ Conference on Medicinal and Aromatic Plants of the Countries of South-Eastern Europe-CMAPSEEC. May 26-29, 2016, Plovdiv, Bulgaria. Abstract Book PP-112.

8. Rodriguez-Delgado MA, Malovana S, Perez JP, Borges T, GarciaMontelongo FJ. Separation of phenolic compounds by high-performance liquid chromatography with absorbance and fluorimetric detection. Journal of Chromatographica. 2001;912(2):249-57.

9. Bevilacqua AE, Califano AN. Determination of organic acids in dairy products by high performance liquid chromatography. Journal of Food Science. 1989:54(4);1076-9.

10. Cemeroglu B. Food analysis. Food Technology Society Publication. Ankara, Turkey. 2007;168-171.

11. Ozgen M, Reese RN, Tulio AZ, Scheerens JC, Miller AR. Modified 2, 2-Azino-bis-3-ethylbenzothiazoline-6-sulfonic Acid (ABTS) method to measure antioxidant capacity of selected small fruits and a comparison to Ferric Reducing Antioxidant Power (FRAP) and 2,2-Diphenyl-1picrylhdrazyl (DPPH) methods. Journal of Agriculture and Food Chemistry. 2006;54(4):1151-7.

12. Melgarejo P, Salazar DM, Artes F. Organic acids and sugars composition of harvested pomegranate fruits. Eur. Food Res. Technol. 2000;211(3):185-90.

13. Bozhüyük MR, Pehluvan M, Kaya T, Dogru B. Organic Acid Composition of Selected Mulberry Genotypes from Aras Valley. Atatürk Univ., Journal of the Agricultural Faculty. 2015;46(2):69-74.

14. Aljane F, Sdırı N. Morphological, Phytochemical and Antioxidant Characteristics of White (Morus Alba L.), Red (Morus rubra L.) and Black (Morus nigra L.) Mulberry Fruits Grown in Arid Regions of Tunisia. Journal of new sciences, Agriculture and Biotechnology. 2016;35(1):1940-7.

15. Jiang $\mathrm{Y}, \mathrm{Nie} \mathrm{W}$. Chemical properties in fruits of mulberry species from the Xinjiang province of China. Food Chemistry. 2015;174:460-6.

16. Iqbal M, Mir K, Munir M. Physico-chemical characteristics of different mulberry cultivars grown under agro-climatic conditions of miran shah, North Waziristan (Khyber Pakhtunkhwa). Pakistan Journal of Agriculture Research. 2010;48(2):209-17.

17. Khalid N, Fawad SA, Ahmed Al. Antimicrobial Activity, Phytochemical profile and trace minerals of black mulberry (Morus Nigra L.) fresh juice. Pakistan Journal of Botany. 2011;43:91-96.

18. Kamiloglu S, Serali O, Unal N, Capanoglu E. Antioxidant activity and polyphenol composition of black mulberry (Morus nigra L.) products. Journal of Berry Research. 2013;3(1):41-51.

19. Arfan M, Khan R, Rybarczyk A, Amarowicz R. Antioxidant activity of mulberry fruit extracts. International Journal of Molecular Sciences. 2012;13(2):2472-80.

20. Lee $\mathrm{Y}, \mathrm{Hwang} \mathrm{KT}$. Changes in physicochemical properties of mulberry fruits (Morus alba L.) during ripening. Scientia Horticulturae. 2017;217:189-96.

21. Sanchez EM, Calin-Sanchez A, Carbonell-Barrachina AA, Mel-Garejo P, Hernandez F, Martinez-Nicolas JJ. Physicochemical characterization of eight Spanish mulberry clones: Processing and fresh market aptitudes. Int. J. Food Sci. Technol. 2014;49(2):477-83.

22. Gecer MK, Akin M, Gundogdu M, Eyduran SP, Ercisli S, Eyduran E. Organic acids, sugars, phenolic compounds, and some horticultural characteristics of black and white mulberry accessions from Eastern Anatolia. Canadian Journal of Plant Science. 2016;96(1);27-33.

23. Natic MM, Dabic DC, Papetti A, Fotiric Akšic MM, Ognjanov V, Ljubojevic M, et al. Analysis and characterisation of phytochemicals in mulberry (Morus alba L.) fruits grown in Vojvodina, North Serbia. Food Chemistry. 2015;171:128-36.

24. Mahmood T, Anwar F, Abbas M, Saari N. Effect of Maturity on phenolics (phenolic acids and flavonoids) profile of strawberry cultivars and mulberry species from Pakistan. International Journal of Molecular Sciences. 2012;13(4):4591-607. 


\section{PICTORIAL ABSTRACT}

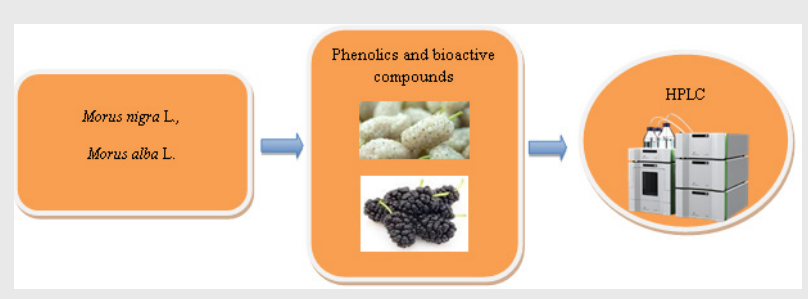

\section{About Authors}

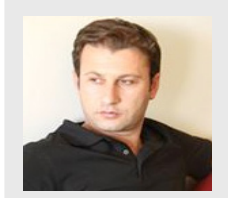

Assoc. Prof. Dr. Muttalip Gundogdu: $\mathrm{He}$ earned his $\mathrm{BsC}$ in Agricultural Engineering, Assoc. Prof. Dr. Muttalip Gundogdu earned his PhD degree on horticulture Yuzuncu Yal University, Turkey. He is interested in fruit breeding since his undergraduate education. He is currently a full-time researcher at Abant azzet Baysal University, Agricultural and Natural Sciences Faculty, Department of Horticulture.

\section{SUMMARY}

- In this study study, biochemical of mulberry species were determined. Black mulberry genotypes were found to contain higher antioxidant capacity than white mulberry genotypes. Malic acid was deterimined as the major organic acid for all the mulberry genotypes. It was followed citric and succinic acid. Also, fumaric acid was determined the lowest level organic acid. Vitamin $C$ and total antioxidant values were differed significantly by cultivars. In the study, Gallic, chlorogenic and routine were identified as the main phenolics. It was determined that the lowest level phenolic compound was ferulic acid.

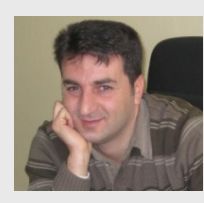

Prof. Dr. Murat Tunçtürk: He earned his BsC in Agricultural Engineering, Prof. Dr. Tunçtürk earned his PhD degree on Industrial Plants Yuzuncu Yal University, Turkey. He is interested in aromatic and andustrial plants since his undergraduate education. He is currently a full-time professor at Yuzuncu Yal University, Agricultural Faculty, Department of Field Crops. He published over 110 peer-reviewed articles and still active on his research area. Additionally, he is a member of scientific commissions about Medicinal and Aromatic Plants at Food and Agriculture in Turkey. He has visited more than 20 different countries for scientific purposes.

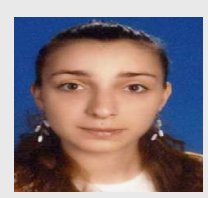

Selma Berk: She is working as a researcher in Department of Plant and Animal Production, Mudurnu Sureyya Astarca Vocational school, Abant Izzet Baysal University. Research interests include biochemical properties of fruits. He contunies breeding and improve new cultivars on fruits.

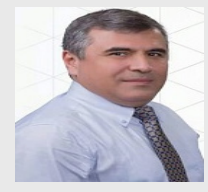

Prof. Dr. Nazim Sekeroglu: He earned his BsC in Agricultural Engineering, Prof. Dr. Sekeroglu earned his PhD degree on Medicinal and Aromatic Plants Cukurova University, Turkey. He is interested in medicinal and aromatic plants since his undergraduate education. He is currently a full-time professor at Kilis 7 Aralak University, Department of Medicinal and Aromatic Plants. He published over 100 peer-reviewed articles and still active on his research area. Additionally, he has organized many international scientific meetings, including congress, symposiums and workshops as chairperson. Furthermore, he is the founder of the Association of medicinal and Aromatic Plants of Mediterranean (AMAPMED), also he is general coordinator of Global Federation of Medicinal and Aromatic Plants (GOFMAP), a worldwide non-profit organization gathering associations related 'Medicinal and Aromatic Plants'. Moreover, he is a member of scientific commissions about Medicinal and Aromatic Plants at Food, Agriculture, Forestry and Health Ministries in Turkey. He has visited more than 50 different countries for scientific purposes.

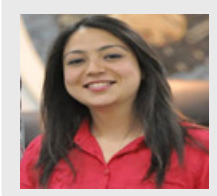

Assist. Prof. Dr. Sevgi Gezici: After completing her Ms in Molecular Biology and Genetic at Department of Biology, Gaziantep University, Turkey, she earned her Ph.D degree in the Molecular Biology and Genetics form the same University. She has received scholarships for her MSc and Ph.D from TUBITAK, which is the best research center in Turkey. She is currently assistant professor at Kilis 7 Aralik University, Department of Molecular Biology and Genetics.

Cite this article: Gundogdu M, Tunçtürk M, Berk S, Sekeroglu N, Gezici S. Antioxidant Capacity and Bioactive Contents of Mulberry Species from Eastern Anatolia Region of Turkey. Indian J of Pharmaceutical Education and Research. 2017;52(4S):S96-S101. 